\title{
Creating a Book Culture \\ In a Special Needs School \\ With Specific Reference to \\ Visually Impaired Learners
}

\author{
Patricia Devenish \\ Educator/Librarian \\ Open Air School \\ South Africa
}

\begin{abstract}
This paper outlines the role played by the library at a special needs school in Durban, South Africa, to create within the school a dynamic and vibrant book culture. The task is a challenging one, because with limited resources, the library staff are endeavoring to create opportunities and circumstances which will facilitate learners who have physical disabilities (including visual impairment), linguistic incompetence and cultural impoverishment, to access the richness of reading, writing, and storytelling and listening. The process began with recognizing the inadequacy of the library. Subsequently, enlarging the library, acquiring 2000 new books, including visually impaired learners and introducing a writing club facilitated a process which is ongoing.
\end{abstract}

\section{Introductory Background}

The Open Air School in Durban, South Africa, opened its doors to physically disabled pupils on $9^{\text {th }}$ February 1921. The school has thus just celebrated its $85^{\text {th }}$ birthday. Today there are 252 pupils who come from all over the province of KwaZulu Natal to complete their academic education. A boarding establishment is situated two kilometers from the school where learners from outlying districts are accommodated.

The classes run from Pre-Primary to Grade 12. There are three classes for the non-academic children where the learning programmes are geared for practical rather than academic learning. In addition to the teaching staff, ongoing therapy is carried out by occupational therapists, physiotherapists, speech therapists and a psychologist. A medical department is staffed by four full time medical nursing sisters. The school calls on the services of various medical specialists on a regular basis.

Other staff members include an accountant who handles all the finances, drivers who also carry out general repairs and maintenance, house mothers and fathers and general assistants who help with cleaning, cooking, and the repair of wheelchairs.

The physical disabilities and conditions vary and include: cerebral palsy from mild to severe; post polio cases; spina bifida; closed head injuries; paraplegics and quadriplegics in wheelchairs as the result of motor vehicle accidents and post gun shot wounds; hearing and visual impairment; cystic fibrosis, severe epilepsy and diabetes, which require ongoing medical monitoring; children who fall within the autistic spectrum with Asperger's and Tourette's syndromes. In addition, many children also experience dyslexia and other learning difficulties. 
Four years ago the school agreed to participate in a programme in which severely visually impaired children were to be admitted. The Society for the Blind provides a facilitator to assist these children. The Occupational Therapists are responsible for assessing and assisting partially blind children and children with limited visual impairment. Twenty percent of learners are visually impaired. This includes five blind children.

The school provides transport for most of the learners. The vehicles are owned and maintained by the school with limited financial assistance from the KZN Department of Education.

Forty percent of the parents are indigent and are unable to pay school fees. The subsidy given by the Department of Education of KwaZulu Natal covers fifty percent of the school=s running costs. The school therefore has to find ways and means of raising money to cover costs. Most of the money raised is through organisations like Rotary and charitable trusts. The school also runs fund raising projects like concerts and fetes.

Of the 252 children, 57\% speak Zulu as a home language, 35\% speak English, 4\% speak Xhosa, $3 \%$ speak Afrikaans and .7\% speak Sotho. We have one Swahili speaking learner. The language of instruction is English. Zulu and Afrikaans are offered as second languages. The school follows the Outcomes Based Education programme but various adaptations and concessions are made to allow for disability.

The children participate in paraplegic sport, provincially, nationally and internationally. The school has a choir who has sung with the KZN Philharmonic Orchestra and also a registered dance company, the LeftfeetFIRST who dance with able bodied dancers and have performed with distinction. Learners participate successfully in art and public speaking competitions.

\section{Management of the library 2003}

In addition to my teaching duties, I took over the management of the school library at the beginning of 2003. This was a well established library. The books had been correctly classified, accessioned and shelved; they had been looked after and were, apart from age, in good condition. We had a dedicated, fully qualified part time librarian paid by the Governing Body of the school.

The Library was, however totally inadequate to serve the needs of the school. Five thousand books were crammed into a room the size of a classroom. There was little space to move about between the bookshelves. This posed a major problem for wheelchairs. It was dark, as bookshelves covered three quarters of the windows. There were no chairs or tables for the children.

The library was under utilized. It was open two mornings per week only. There were no timetabled Library periods. There were few organised visits to the library. The books were old and outdated. Nor were there any Zulu books. The children were not 
involved in helping to run the library and there was no sense of ownership. There was no incentive to return books on time and no effort was made to retrieve lost books. In addition, no provision had been made for the visually impaired children.

All these factors were compounded by the fact that the library had had no funding allocated to it since 1994. These deficiencies were partly the result of the changes which occurred in education during the 1990's in South Africa which included the loss of a fulltime librarian's post and the drastic cut in the Departmental subsidy to the school.

\section{Expansion of the library}

My first concern was to acquire a budget for the library. The principal agreed to give us R4000.00 (approximately $\$ 700.00$ ) for one year. Since that time we have requested funds to purchase books. The principal has agreed to meet the cost on each occasion. We began ordering new and up to date books for the children, including stories written in Zulu. Numerous old and obsolete books were weeded out and disposed of. I contacted the Tape Aids for the Blind Society who began lending us stories on tapes for the visually impaired learners. We also acquired some CDs of classical literature, classical music, modern pop and African music.

After consideration, it was decided against introducing brailed books for the blind children. Brailed books are cumbersome. Their life span is limited and we would have to borrow them from the Braille Library in Grahamstown. We decided that it would be better for the blind children to become members of this library and to receive their books directly. At present all our blind children are in the Junior Primary School and are still learning to read Braille.

The Librarian and I, together with the Principal, set about planning the expansion of the Library. Application was made to a charitable Trust left by the late Mr. Victor Daitz. Money was granted to us to expand the library, doubling its size. Named after the benefactor, the Victor Daitz Media Centre was officially opened on $25^{\text {th }}$ November 2004.

A major consideration during the planning was to make the library wheelchair friendly. An extra wide doorway was made which allows the passage of two wheelchairs at a time. Wide spaces between the bookshelves and the clusters of new chairs and tables (donated by the Union of Jewish Women) make it easier for wheelchairs to move around. Chairs are also placed in the aisles to accommodate learners on crutches who cannot stand while they browse through books. A sturdy blue carpet, able to take the strain of wear and tear caused by wheelchair tyres and crutches, was laid down. Bright orange curtains help to make the room a cheerful place as orange is known as a colour which promotes health. We installed a video machine in the library and a number of videos for the children to watch were donated. In addition, an ex-member of staff joined the library as a volunteer.

Air conditioners help to make the library a pleasant place in the hot, humid Durban weather. A special corner of the room was put aside for the Foundation Phase 
learners (i.e. Grade 0-3 learners aged between 6 and 9 years of age) where no one else is allowed to go.

The physical expansion of the library immediately made it more accessible. In 2005 weekly or fortnightly library periods were time-tabled for every class. The opening times of the library were extended to include half an hour before school starts and during every lunch break. Because the children are bussed home after school every day the library cannot remain open in the afternoons as is the case with mainstream schools. This puts the learners, especially the seniors, at a great disadvantage.

The installation of a computer programme in the library has streamlined our accession process, stock control and record of books taken out. We have maintained the card catalogue for learners to consult. It is to be hoped that soon the library will have access to the Internet.

National and International holidays, (Freedom Day, Human Rights Day) major religious festivals (Easter, Christmas, Eid, Diwali), cultural events (Heritage Day) as well as environmental issues are highlighted in the library by weekly displays. We also mark fun events such as Valentine's Day and Halloween. The Senior Special Class has been assigned to assist with doing research and setting up these displays. Thus we are acknowledging all the cultures in the school.

A large notice board outside the library is used to display newspaper cuttings making the children aware of current events both in South Africa and in the world. The children's art work is displayed in the library. The library is used for choir practice every week, for speech competitions, creative writing classes and teachers' workshops.

\section{Assessment of the improved library}

As a result of the improvements, a greater number of children are coming in to take out books and browse during the lunch break. The library has become a child friendly and welcoming place.

The Foundation Phase children (Grades 1-3) are our Astar@ readers. Good reading habits have been established because their teachers have brought them into the library on a regular basis to choose and change books. In addition these teachers take out 20 to 30 books at a time to keep in their classrooms to read to the children. The Grades

$4 \mathrm{~s}$, 5s and 6s (10 to 13 year olds) who have recently come through the Foundation Phase are also taking out books on a regular basis.

However a problem remains with the high school. With the introduction of over 2000 new books, we believe we have a well stocked library with books for every level of reader. We have a variety of books including those written with a South African background by African and South African authors. Yet the books remain on the shelves. The high school children love to come into the library to chat, to look at a magazine or Archie comic but the only books they will take out are the books they need for projects 
for their learning areas. There are exceptions. We do have a small number of regular readers.

The fact that children are reading less is a world wide phenomenon. Many factors contribute to this decline and these operate at Open Air School. However we believe that perhaps other factors were contributing to the lack of a book culture among our children. The first consideration would be that of disability. How does a physical disability make a trip to the library a difficult one? With the enlargement of the library the problem of accessibility, a major problem for those in wheel chairs disappeared. However we still have high shelves that are beyond the physical reach of someone in a wheelchair. Learners with spasticity or those with only one operative hand may also experience difficulty in taking down a book and handling it.

Nonetheless, we found that these conditions do not cause major problems as there are sufficient people to assist anyone who asks for help. We have three adult librarians, two senior girls whom we have trained as monitors and a group of children known as ABook Buddies@ who undertake to help anyone who asks for it. The ABook Buddies@ are volunteers and my first ABook Buddy@ was a Grade 8 learner who operates from a motorized wheelchair using the toes of his right foot, the only part of his body over which he has control. He is proud of the fact that he can find any book in the library and when someone asks for assistance he will take the child to the correct shelf and point to the required book with his foot!

\section{Visual impairment}

Visual impairment presents a serious challenge in a library. The degree of impairment varies. Some of the learners need only slight enlargement of the text to read. Others require considerable enlargement. Some read with the aid of a strong light, others use a magnifying glass. For some, especially the albino children, a piece of tinted plastic placed over the page helps to reduce the glare from the white paper.

To assist the visually impaired learners we have systematically marked large print books with bright orange stickers on the spines. We have also identified all our visually impaired learners. When a visually impaired learner takes out a book we check that the learner can read it comfortably.

Because the reading skills of visually impaired learners are generally very much below average, we believed it would be beneficial for these learners to listen to stories on tapes supplied by the Tape Aids for the Blind. Children with severe dyslexia will also benefit from listening to tapes.

Unfortunately, learners have been reluctant to take out tapes. All tapes come in identical blue plastic boxes. It is impossible to judge the stories, as one can do with a printed book, by looking at the picture on the cover, reading the blurbs and reading the first page. With the taped book, unless we know it, we have only the title to go by. The children can listen to the start of the tape in the library and then decide whether they want to take out the tape or not. But they choose not to do this. 
Earlier this year I had an interview with the chief librarian of Tape Aids. We decided to select the books to be taped from our own library, selecting books that have proved popular instead of relying on Tape Aids to choose for us. We are now waiting for these books to be read on to tape and delivered to us. The waiting period is quite lengthy as Tape Aids relies on volunteer readers. We hope that we will find a way to make the taped stories accessible to our visually impaired learners.

\section{Programme for blind children}

At present there are five blind children in the school and they are all in the Junior Primary Section. Due to a lack of stimulation, these children have poor language skills, poor fine motor skills and poor listening skills. During the library period these children were being sent to therapy. I had hoped that the blind children would come to the library with the rest of the class. They would be able to listen to a taped story while their classmates browsed. We also hoped that the teachers would play a taped story to the class, or read a story in the library to the class. This has not happened and the blind children have been deprived of the opportunity of being part of the library.

After discussion with the chief occupational therapist of the school, I have formed a story club for the blind children. They have a library period with me once a week when I read them stories or they listen to a story on CD or tape. We also talk about the stories and discuss them. Every week I read five short stories (lasting between 1 minute and 3 minutes) onto tape for each one of them to take home and listen to. Sometimes I play the guitar and we sing songs together. This is a very new venture and I hope to extend it to include some drama and puppets.

\section{Social and economic factors}

There are also a number of other roles that disability plays in contributing to a lack of a book culture. Physically disabled children are often very passive, lacking in initiative and expecting others to do things for them. One of the challenges at the school is to make learners as independent as possible. We took the following steps to create among the learners a sense of ownership for the library. During the library periods the children are taught how the library runs and are encouraged to use the Dewy System to find information. Children are encouraged to return their books on time and a fine of 5 cents per day for overdue books has begun to make them more responsible.

Disabled children lack many of the life experiences that able bodied children enjoy. Some children have never been to the beach or swum in the sea. Some have never been to a supermarket, or ridden on an escalator. Often they are left at home when the rest of the family goes out because the family does not have a car. Disabled children may also spend months in hospital where they are not stimulated intellectually.

Language skills are often lacking in disabled children because early language training has been neglected. The majority of our parents are deeply committed to caring for their children and providing them with the best they can afford but when a parent has to battle with feeding, bathing, walking, and toilet training with a disabled child, then 
reading and telling stories may come rather low on the list of priorities. And when the parents are poor and there are perhaps no books in the house then the chances of the child listening to a bedtime story are remote.

\section{Language policy, culture and disability}

There are 178 children in the high school. Of these 37 English speak as their home language, 143 speak Zulu, and there are 21 other children who speak Xhosa, Sotho or Afrikaans. Therefore 21 percent of the high school is English speaking and 79 percent of the high school is non-English speaking.

In South Africa today many parents are choosing to have their children educated in English rather than in an indigenous language. English is seen as the language of power. It is the language of textbooks, business, the internet and the movies. Parents are anxious that their children speak and write English otherwise it restricts their opportunities later in life.

The medium of instruction at the Open Air School is English. The majority of children who are referred to us come with a very poor command of English. If, after assessment, it is felt that the child has the potential to cope academically, then the child is accepted even though the child=s ability to speak or write English is severely limited.

The English language teachers therefore teach English at a lower level than would be expected. Extra English lessons and remedial classes are offered in an effort to bring the children=s language skills up to standard. Unable to communicate clearly in English, the children battle in other learning areas like mathematics, and business economics. In addition the non English speaking children are offered their home languages as second languages. Thus their own languages are not being sufficiently developed. Under these circumstances it is understandable that there is little incentive to take out a library book and read for pleasure. To read a book in one=s second language is a demanding exercise. More effort is needed in decoding the language and in the effort to do this, the meaning is often lost.

The English speaking children also suffer. They are few in number. The level of English offered in class is designed to meet the needs of the majority, the non English speaking child and English speaking children remain unchallenged.

The Zulu, Xhosa and Sotho speaking children come from a rich oral tradition which is now being eroded by urbanisation and modernisation. It has not been replaced by a book culture. Language is also intimately tied to culture. The culture of Open Air School derives from an English language tradition which is different to the schools from which the majority of children come and which sometimes seems alien to the children. (e.g. the house system). The English speaking members of staff are often unaware of the cultural nuances of the non English speaking cultures. Non English speaking members of staff do not have the confidence to promote their cultures in a predominantly English speaking setting. Thus the traditions and cultures of the non English speaking learners are neglected. 


\section{Survey on Reading}

I conducted a survey amongst the high school learners to ascertain the reading habits of the children. I conducted it along language lines, dividing the learners into two groups, Non-English Speaking (88 learners participated) and English speaking (30 learners participated). Each question was explained to the learners before they answered it. The results of the survey are summarized in the table below:

\begin{tabular}{|l|c|c|}
\hline \multicolumn{1}{|c|}{ Children } & $\begin{array}{c}\text { Percent of English } \\
\text { Speaking Children }\end{array}$ & $\begin{array}{c}\text { Percent of Non English } \\
\text { Speaking Children }\end{array}$ \\
\hline $\begin{array}{l}\text { Who remembered being told stories when } \\
\text { young }\end{array}$ & $86 \%$ & $89 \%$ \\
\hline $\begin{array}{l}\text { Who remembered being read stories when } \\
\text { very young }\end{array}$ & $70 \%$ & $66 \%$ \\
\hline Who owned no books of their own & $3 \%$ & $27 \%$ \\
\hline Who owned many books & $30 \%$ & $2 \%$ \\
\hline $\begin{array}{l}\text { Who belong to municipal libraries } \\
\text { Who have taken out more than 5 books } \\
\text { from the school library between January and } \\
\text { April 2006 }\end{array}$ & $80 \%$ & $2 \%$ \\
\hline $\begin{array}{l}\text { Who have taken out more than 10 books } \\
\text { during this period }\end{array}$ & $43 \%$ & $40 \%$ \\
\hline Who have written a story on their own & $30 \%$ & $5 \%$ \\
\hline Who have a computer at home & $67 \%$ & $32 \%$ \\
\hline $\begin{array}{l}\text { Of these the number who have access to the } \\
\text { WWW }\end{array}$ & $80 \%$ & $43 \%$ \\
\hline
\end{tabular}

1 A high percentage of children remembered being told stories when young. However fewer non English speaking children remembered being read stories when very young.

227 percent of non English speakers indicated that they owned no books of their own whereas only 3 percent of English speakers indicated this. 2 percent of non English speakers indicated that they owned many books whereas 30 percent of English speakers indicated that they owned many books.

32 percent of non English speakers belong to municipal libraries whereas 80 
percent 80 percent of English speakers belong to municipal libraries.

440 percent of Non English speakers have taken out more than 5 books from the school library between January and April 2006. 43 percent of English speakers have taken out more than 5 books during the same period.

9 percent of non-English speakers have taken out more than 10 books during this period. 30 percent of English speakers have taken out more than 10 books during this period.

5 The survey reveals that the most widely read magazine by both groups to be the same, a tabloid English magazine called YOU.

659 percent of non English speakers have written a story on their own. 67 percent of English speakers have written a story on their own. 70 percent of the stories of both groups were lost.

7 Both groups enjoy reading the following types of stories in order of popularity: Adventure Mystery Love

832 percent of non English speakers have a computer at home. Of these 43 percent have access to the WWW.

80 percent of English speakers have a computer at home. Of these 50 percent have access to the WWW.

Thus approximately only 12 of the 141 non English speakers in the high school have access to the WWW and approximately 12 English speakers out of 37 have access to the WWW.

It appears therefore that the non-English speaking learners who are in the vast majority are definitely more disadvantaged than the English speaking learners.

\section{The Vulumoya Dancing Pencils Writing Club}

The steps taken by the library staff outlined thus far concentrate mainly on reading and listening. However writing is an important skill which should also be developed. I have attempted to cultivate a love for writing is by introducing a writing club into the school.

The catalyst to do this was the publication of a book of poetry by one of our Grade 11 learners in 2004. The psychologist had approached me with an exercise book of poems written by a learner suffering from depression as a result of cancer. The psychologist hoped that we could help her by "doing something" with her poems. I agreed. I had heard about Felicity Keats who published children's work and I approached her with a view to publishing Lungile's poetry. Mrs Keats' reply was that she published work done only by the children in her writing clubs. The learner duly joined a Dancing Pencils Writing Club and the publishing company started by Mrs Keats, UmSinsi Press published her poems. The title of the book Let me be Me is taken from the first poem in the book. 
The publication of this book was of course very important for the young poet but it has also spurred our senior learners on to write poetry themselves. I am often approached by a grade 11 or 12 learner with a poem that they've written. When we had our speech and drama festival last year ten senior learners recited poems they had written themselves. At the beginning of this year I ran a Valentine Day Poetry Writing Competition. The best poem, "Love Came” submitted by a Grade 12 learner was outstanding, especially if one considers that he was writing in his second language.

Felicity Keats began her writing clubs for children when she made two important discoveries: firstly, that children can write stories, secondly that children enjoy reading stories written by other children. She established UmSinsi Press, a non profit making organization when she could not find a publisher to publish the stories her children wrote. "UmSinsi" is the Zulu name for the lucky bean tree.

Felicity Keats will not allow people to start a Dancing Pencils Writing Club unless they undergo her three day training course which qualifies them as a "mentor." Her success in getting children to write creatively lies in her insistence that children write in a non-judgmental, non-threatening atmosphere which allows them to tap into the creative right brain. In her book, Dancing Pencils right brained 'how to' for writers and teachers, Felicity Keats aptly describes the experience one has in watching children writing creatively;

"A feeling of amazement and of harmony fills me as I look at a sea of dancing pencils. There have been as many as two hundred heads bent low over their papers, the pencils moving rapidly to total silence - or to perhaps the soft background sound of classical music ...

Strangely it is possible to tell when the learners have entered a rightbrained or creative state. Something shifts in the atmosphere. Something imperceptible, but there comes a moment when I know they have shifted and are writing creatively. The body language is different. There is fluidity, a harmony of body, mind and spirit with just the quiet dancing pencils moving over the unlined paper." (Keats 1999 page 8)

Last year I started a Dancing Pencils Writing Club at the School, making it part of the Grade 7 English Programme. The name of the club, "Vulumoya" chosen by the children is a Zulu word which translates as a "free and open blowing wind". It fits in with the name of our school, the school song and our national anthem. At the end of last year we published a volume of stories and poems written by the grade sevens, Vulumoya Stories and Poems. The children designed the cover themselves. The pride and joy that the children felt in seeing their stories and names in print can be appreciated.

This year I opened the Vulumoya Writing Club to the whole school. I have at present 17 members from Grade 4 to Grade 11 who write one hour a week in the Library.

After a number of writing sessions the children are asked to choose one of their 
pieces of writing. They make a neat copy of the story, if necessary make some changes, and then hand it in to their teacher for editing. These stories are never marked. The editing must be done in a sensitive way. While the obvious errors in spelling and punctuation must be corrected, the child's story must not be tampered with. The mentor may not "improve on" the plot or the characters. Quaint or unusual ways of expression, even though not strictly idiomatic, should be retained if the meaning is clear. It is always possible to discuss a point with the young writer and sort the problem of meaning out. The children are encouraged to illustrate their stories and they are then submitted for publication.

Is it really possible to use Felicity Keats's method of teaching creative writing with learners writing in their second language with poor writing skills? I believe it is. The right brain does not work with words but with images and pictures. When writers enter that creative state they are then experiencing what they are imagining. Even when the vocabulary is limited, the grammar incorrect, and the spelling chaotic, the emotional experience can still be conveyed.

As an example of this I would like to describe how this method works by relating it to one of the Grade 7 learners, a boy from rural KZN. His English was extremely limited. He shook his head when I told the class they were going to write stories for a book. "Not me, miss. I can’t write."

One of our early exercises was to listen for a sound. The learner heard the sound of clapping. This is part of what he wrote down during the initial writing session:

“Tip,Tap,- - -Tap. Wait a moment I hear something. I hear a hands, hands clapping I clap and guess what we are clapping. The sound clap is hear. Ho-hoho-ho and clap the way you go Let's start I,2,3, go clap clap respect clap celebrating clap clap”

"It's nonsense, miss" he said to me afterward. But I said, "There's a rhythm there. Let's clap it out.” We did this and with some guiding questions from me, the poem, "Clap clap" was written and published. This boosted the learner's self image immensely but it also stimulated his desire to improve his English. He spent the rest of the year with a dictionary tucked into the side of his wheelchair, determined to learn three new English words daily.

Felicity Keats has established Dancing Pencils Writing Clubs all over South Africa, in urban areas, in African townships and in even in the deepest rural areas where one has to cross rivers to get to the schools. The children write in the language of their choice. The Education Departments of Mpumalanga and KwaZulu Natal (two of the nine provinces in South Africa) have ordered copies of the UmSinsi books to use in the schools. The Provincial Library in KwaZulu Natal has ordered a number of books to be placed in their libraries. Among the titles are Let Me Be Me and Vulumoya Stories and Poems. 
The opportunity to write without one's work being criss-crossed by a red pen, to write without fear of criticism and rejection, has given our children self confidence and helped boost their self esteem. Seeing their stories and their names in print has engendered a pride in themselves. These positive feelings associated with books have certainly helped to begin the creation of a book culture in the school.

\section{The way forward}

I have realised that creating a book culture is a journey. Although we have begun we have not yet arrived. We have succeeded in creating a spacious, light-filled library filled with books and art work which the children love. We have endeavoured to meet the needs of the visually impaired children and partially succeeded. Our junior learners are making good progress in reading and slowly the children are learning that the library belongs to them and that if they learn how to use it, it will help them in their schoolwork. We have stimulated an interest in poetry writing among our seniors and established a writing club which incorporates learners from 10 to 18 years of age. The children have published two books.

There is still much we need to do. The most important project in the near future will be to introduce storytelling in the school. We need to keep alive the wonderful, oral tradition of the indigenous people of our land and to pass it on.

We need to widen the awareness of the importance of books and the need to be creating a book culture not only in the library but in every department of the school. The journey takes place within the confines of the school, deepening and enriching all who participate. When the learners leave they will take this book culture out into the world with them. But within the school the journey continues. For all of us at Open Air School this should be part of a life-long learning experience.

"We shall not cease from exploration And the end of all our exploring Will be to arrive where we started And know the place for the first time."

T.S. Eliot “Little Gidding” from Four Quartets

\section{References}

Behr, A.L. (1973). Methods and Techniques in Educational and Psychological Research: JL van Schaik Limited Pretoria

Devenish P.M. Ed. (2005). Vulumoya Stories and Poems: UmSinsi Press

Gilham B Ed (1986). Handicapping Conditions in Children: Croom Helm 
Haarhoff D. (1998). The Writer's Voice; A workbook for writers in Africa: Zebra Press

Hobday A. \& Ollier K. (1999). Creative Therapy with Children and Adolescents: Impact Publishers Inc.

Keats F. (1999). Dancing Pencils; Right-brained "How to" for writers and teachers: UmSinsi Press

Moyo T (2002). Mother tongue versus an ex-colonial language as media of instruction and the promotion of multilingualism: the South African experience:

SA Journal for the Afrikaans language

Myeni L (2004). Let Me Be Me: UmSinsi Press

Pretorius E. \& Ribbens R (2005). Reading in a disadvantaged high school: issues of accomplishment, assessment and accountability: South African Journal of Education Vol (25) 3 139-147

Russell P. (1978). The Wheelchair Child: Souvenir Press (E and A) Ltd

\section{Author note}

Patricia Devenish has taught at the Open Air School in Durban, South Africa since 1990.

At present she manages the school library and teaches classes in the Senior Phase of the school (12-14 years of age). She majored in English and History at the University of the Witwatersrand and graduated with an honours degree in English from the University of South Africa. She attended the Rose Bruford College of Dramatic Art in Kent, England and holds two licentiates in Speech and Drama. Her interests lie in developing creativity in children through poetry, story writing, drama, music, art and dance. 
Reproduced with permission of the copyright owner. Further reproduction prohibited without permission. 